\title{
UV irradiation inhibits $A B C$ transporters via generation of ADP-ribose by concerted action of poly(ADP-ribose) polymerase-1 and glycohydrolase
}

\author{
IE Dumitriu', RE Voll', W Kolowos ${ }^{1}$, US Gaipl ${ }^{1}$, P Heyder ${ }^{1}$, \\ JR Kalden ${ }^{1}$ and M Herrmann ${ }^{\star, 1}$ \\ 1 Department of Internal Medicine III, Institute for Clinical Immunology, Friedrich- \\ Alexander University of Erlangen-Nuremberg, Germany \\ * Corresponding author: M Herrmann, Department of Internal Medicine III, \\ Institute for Clinical Immunology, Friedrich-Alexander University of Erlangen- \\ Nuremberg, Glückstrasse 4a, 91054 Erlangen, Germany. Tel: + 49913185 \\ 36345; Fax: + 49913185 35776; E-mail: martin.herrmann@med3.imed. \\ uni-erlangen.de
}

Received 19.3.03; revised 29.8.03; accepted 14.10.03; published online 12.12 .03 Edited by Dr M Piacentini

\begin{abstract}
ATP-binding cassette $(A B C)$ transporters are involved in the transport of multiple substrates across cellular membranes, including metabolites, proteins, and drugs. Employing a functional fluorochrome export assay, we found that UVB irradiation strongly inhibits the activity of $A B C$ transporters. Specific inhibitors of poly(ADP-ribose) polymerase-1 (PARP1) restored the function of $A B C$ transporters in UVB-irradiated cells, and PARP-1-deficient cells did not undergo UVBinduced membrane transport inhibition. These data suggest that PARP-1 activation is necessary for ABC transporter functional downregulation. The hydrolysis of poly(ADPribose) by poly(ADP-ribose) glycohydrolase (PARG) was also required, since specific PARG inhibitors, which limit the production of $A D P$-ribose molecules, restored the function of ABC transporters. Furthermore, ADP-ribose molecules potently inhibited the activity of the $A B C$ transporter Pglycoprotein. Hence, poly(ADP-ribose) metabolism appears to play a novel role in the regulation of $A B C$ transporters.

Cell Death and Differentiation (2004) 11, 314-320. doi:10.1038/

sj.cdd. 4401348

Published online 12 December 2003
\end{abstract}

Keywords: $A B C$ transporters; PARP-1; PARP-null cells; PARG

Abbreviations: 3-AB, 3-aminobenzamide; $C F S$, carboxyfluorescein succinimid ester; DPQ, 3,4-dihydro-5(4-(1-piperindinyl)butoxy)-1(2H)-isoquinoline); $\quad \mathrm{INH}_{2} \mathrm{BP}, \quad$ 5-iodo-6-amino-1,2benzopyrone; PARG, poly(ADP-ribose) glycohydrolase; PARP1, poly(ADP-ribose) polymerase; PN, peroxynitrite

\section{Introduction}

Active transport across membranes is a vital function of cells and is often served by members of the $A B C$ transporter superfamily. ${ }^{1-3}$ They transport across extra- and intracellular membranes a wide variety of substrates, including sugars, amino acids, peptides, proteins, ions, hydrophobic compounds, and metabolites. ${ }^{1}$ In addition to two transmembrane domains that form a channel-like structure, $A B C$ transporters contain two cytosolic ATP-binding domains, ${ }^{4}$ which are highly conserved among ATP-binding proteins and ATPases. To date, 48 characterised human $A B C$ genes have been described. ${ }^{3}$ The substrate spectra and the inhibitor profiles of $A B C$ transporters markedly overlap. ${ }^{5}$

$A B C$ transporters play a role in the maintenance of membrane lipid bilayer and in the transport of fatty acids and steroids. ${ }^{3}$ It has been suggested that the $A B C$ transporter $A B C A 1$ induces modifications in lipid distribution of plasma membrane, evidenced by exofacial flopping of phosphatidylserine. ${ }^{6}$ Furthermore, ABC1 was shown to be involved in engulfment of apoptotic cells. ${ }^{7,8}$

One of the physiological roles of $A B C$ transporters is detoxification by extrusion of various toxic compounds from the cytoplasm. ${ }^{9-11}$ Detoxification is particularly crucial when cell injury occurs. In particular, stimuli like UVB irradiation cause the intracellular generation and possibly the accumulation of toxic metabolites. However, little is known on the regulation of active transport through cellular membranes in damaged cells and, in particular, on the regulation of $A B C$ transporters function.

To address this issue, we used a functional export assay employing anionic fluorochromes ${ }^{10}$ after UVB irradiation of peripheral blood lymphocytes. Our results are consistent with a functional paralysis of $A B C$ transporters in UVB-irradiated cells, due to the generation of poly(ADP ribose) molecules.

\section{Results}

UVB irradiation inhibits the export of anionic fluorochromes mediated by $A B C$ transporters

First, we characterised typical features of the active export of anionic fluorochromes from circulating lymphocytes. As anionic substrates of membrane transporters we tested fluorescein (F), carboxyfluorescein (CF), and carboxyfluorescein succinimid (CFS), generated by intracellular esterases from their membrane-permeable diacetate esters. $\mathrm{F}$ and $\mathrm{CF}$ displayed rather rapid extrusion kinetics and were, therefore, not suitable to study the export activities for longer periods. In contrast, human lymphocytes exported CFS over a $400 \mathrm{~min}$ observation time as demonstrated by a progressive reduction of cell-associated fluorescence. The export of CFS was temperature dependent and virtually blocked at $4{ }^{\circ} \mathrm{C}$ (Figure 1a). Oligomycin, an ATP-depleting agent, ${ }^{12,13}$ partially inhibited the fluorochrome export (Figure 1b), confirming that the export is dependent on ATP. Furthermore, the wellcharacterised modulators of $A B C$ transporters cyclosporine 

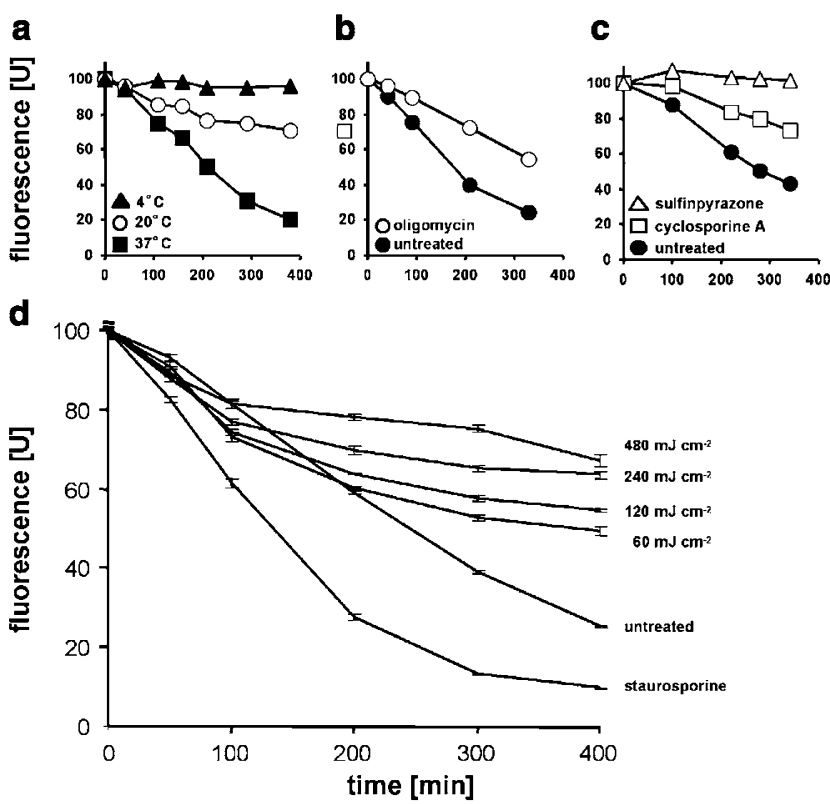

Figure 1 Fluorochrome export by ATP-dependent membrane transporters is inhibited by UVB irradiation. The efflux of CFS from human lymphocytes was dependent on temperature (a) and ATP (b). Treatment with established chemical modulators of $A B C$ transporters (c) or UVB irradiation (d) inhibited the export of CFS. UVB doses are depicted in $\mathrm{mJ} / \mathrm{cm}^{2}$. The decrease of the cellular fluorescence caused by the export of the anionic fluorochrome was measured by flow cytofluorometry. Results from a representative experiment performed in pentaplicates are shown

A, sulfinpyrazone (Figure 1c), verapamil, and probenecid (not shown) inhibited the export of anionic fluorochromes. The partial inhibition of fluorochrome export observed after oligomycin treatment was due to partial ATP depletion at the end of the observation interval.

Next, we studied the effect of UVB irradiation on the export of CFS. A substantial inhibition of fluorochrome export was observed in UVB-irradiated lymphocytes, at doses as low as $60 \mathrm{~mJ} / \mathrm{cm}^{2}$ (Figure 1d). A similar inhibition of fluorochrome export occurred in monocytes and granulocytes after UVB exposure. When we tested alternative fluorochromes including $\mathrm{F}, \mathrm{CF}$, and rhodamine 123 , which are substrates for various $A B C$ transporters, $, 14,15$ we observed a dosedependent UVB-induced inhibition of export as well (not shown).

\section{UVB-induced inhibition of ABC transporters does not correlate with apoptosis or energy deprivation}

Less than $5 \%$ of the UVB irradiated cells, which were gated in our export assays, did bind AxV during the 400 min observation period. To further exclude that the inhibition of anion transporters is due to UVB-irradiation-induced apoptosis, we irradiated lymphocytes in the presence of the broad-spectrum caspase inhibitor z-Val-Ala-Asp-fluoromethylketone (zVADfmk). ${ }^{16-18}$ Incubation with zVAD-fmk inhibited apoptotic cell death for at least $24 \mathrm{~h}$ (Figure 2a). However, it did not restore the fluorochrome export in UVB-irradiated cells (Figure 2b). Conversely, staurosporine ${ }^{19-21}$ that induced efficient and early lymphocyte death via apoptosis (Figure 2a) did even
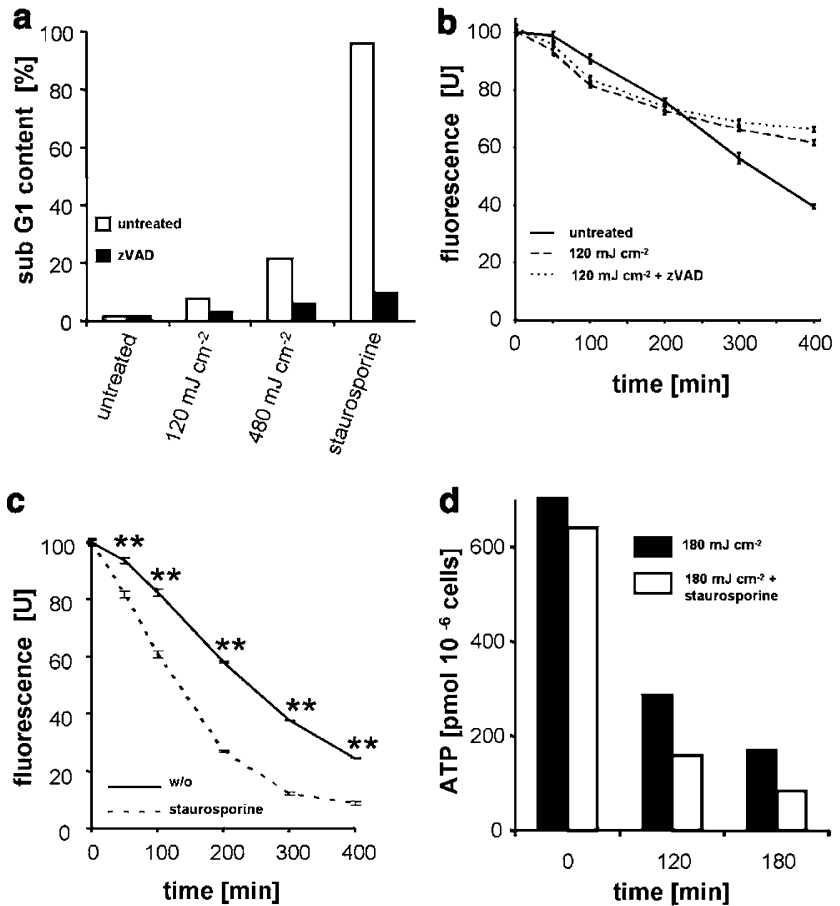

Figure 2 The UVB-induced inhibition of CFS export does not correlate with apoptosis or ATP deprivation. Treatment with the broad spectrum caspase inhibitor ZVAD-fmk inhibited apoptosis (a), while it did not restore CFS export from irradiated PBL (b). Induction of apoptosis with staurosporine increased the fluorochrome export (c) compared to untreated cells. Staurosporine-treated UVB-irradiated cells that had preserved their fluorochrome export ability (c) displayed a lower ATP level compared to cells that have only been irradiated (d). Therefore, the inhibition of the fluorochrome export was not caused by the induction of apoptosis or by deprivation of ATP. UVB doses are depicted in $\mathrm{mJ} /$ $\mathrm{cm}^{2}$. Representative results from one out of at least three independent dye export assays performed in pentaplicates are shown. Highly significant $(P<0.01)$ values were marked with a double asterisk

increase the fluorochrome export (Figure 2c), indicating that apoptosis per se does not downregulate the activity of $A B C$ transporters.

The function of $A B C$ transporters is strictly dependent on ATP. To exclude that ATP depletion is the reason of reduced pumping activity after UVB irradiation, we determined the cellular ATP content. There was a reduction of ATP levels $2 \mathrm{~h}$ after irradiation (Figure 2d). However, in staurosporinetreated UVB-irradiated cells, which display a significantly increased fluorochrome export (Figure 2c), the ATP concentration was even lower than in cells that were only UVB irradiated (Figure 2d). This was observed for all UVB doses and time points tested. Therefore, the remaining ATP is sufficient to supply the energy necessary for fluorochrome extrusion by the membrane transporters. The loss of membrane export activity is not due to energy deprivation.

\section{Inhibition of ABC transporters by UVB irradiation is mediated by PARP-1}

UV-irradiated cells undergo oxidative stress, mostly due to the generation of peroxynitrite $(\mathrm{PN}) .{ }^{22}$ We therefore investigated if $\mathrm{PN}$ influenced the fluorochrome export. Despite the very 

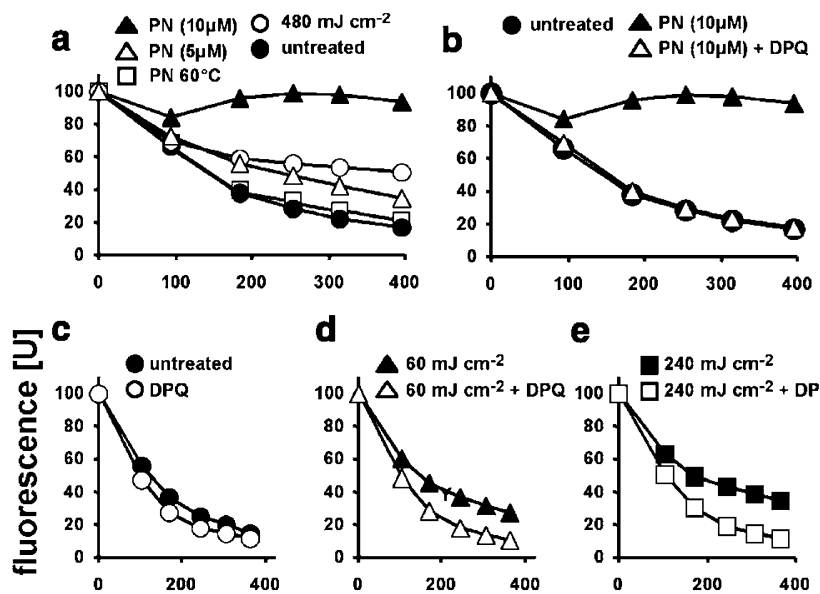

d

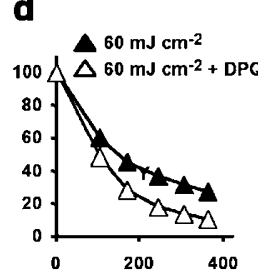

Q
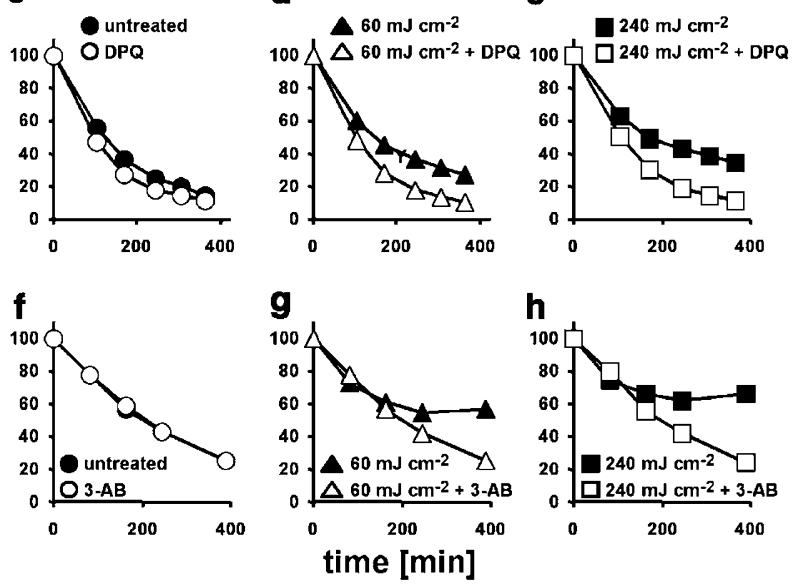

Figure 3 PARP activation mediates the UVB-induced inhibition of dye export from irradiated cells. PN treatment abolished CFS export (a), mimicking the effect induced by UVB irradiation. The effects of PN (b) and of UVB irradiation (c-h) were completely reversed by inhibitors of PARP (DPQ and 3-AB). UVB doses are depicted in $\mathrm{mJ} / \mathrm{cm}^{2}$. The decrease of the cellular fluorescence caused by export of CFS was measured by flow cytofluorometry. Representative results from one out of at least three independent experiments are shown

short half-life of approximately $1.5 \mathrm{~s}$, PN completely abolished the fluorochrome export at a concentration of $10 \mu \mathrm{M}$ (Figure 3a). PN damages DNA with subsequent PARP-1 activation. $^{23}$ Addition of 3,4-dihydro-5(4-(1-piperindinyl)butoxy)-1(2H)-isoquinoline (DPQ), ${ }^{24}$ a selective inhibitor of PARP-1, completely restored fluorochrome export from PNtreated BPL (Figure $3 b$ ). Figure $3 c-h$ shows that the PARP-1 inhibitors DPQ and 3-aminobenzamide (3-AB) ${ }^{13}$ completely restored the fluorochrome export from irradiated lymphocytes regardless the dose of UVB they received.

To confirm the role of PARP-1 in the UVB-induced inhibition of membrane transporters, we used spleen cells from PARP$1^{-1-}$ mice and wild-type littermate controls. We adapted the time kinetic of the dye export since murine lymphocytes displayed an increased dye export activity when compared to human samples. There was a statistically significant dosedependent inhibition of anion export following UVB irradiation in the wild-type cells (Figure 4a). The activity of membrane transporters was restored by treatment with inhibitors of PARP-1 (Figure 4b,c), confirming the results observed with human lymphocytes (Figure $3 c-h$ ). In contrast, UVB irradiation did not inhibit the export of fluorochromes of spleen cells from PARP $-1^{-1-}$ mice (Figure 4d). Treatment with PARP-1 inhibitors did not change the activity of membrane transporters in PARP-1-deficient cells (Figure 4e,f). Similar results were obtained using UVB-irradiated lymph node cells from PARP $-1^{-1-}$ mice.

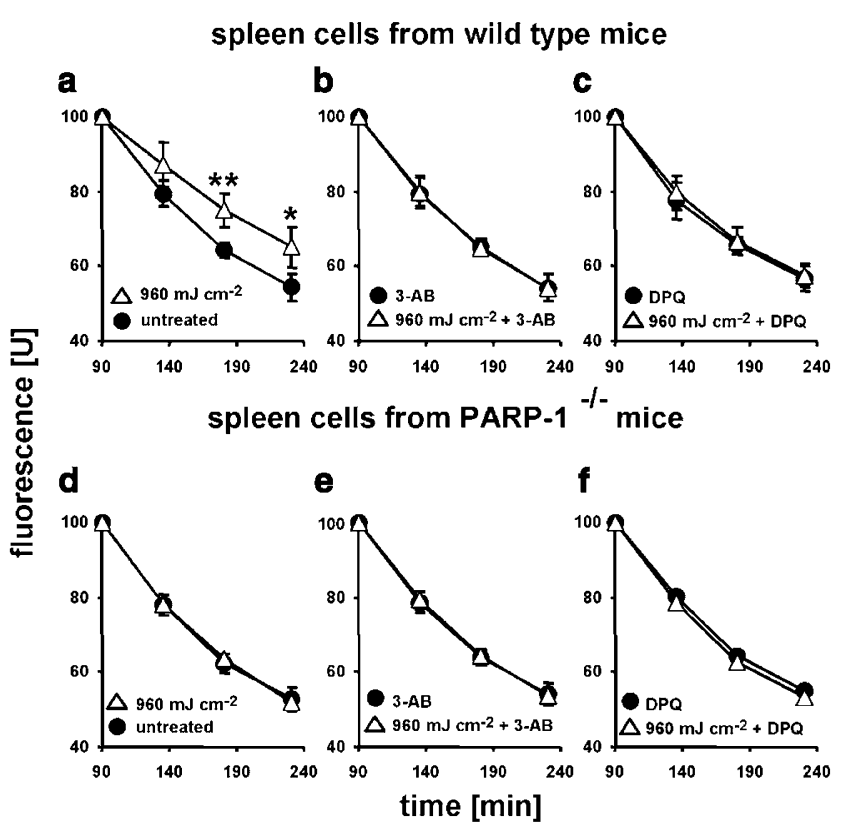

Figure 4 UVB radiation inhibits CFS export from spleen cells of wild-type mice but not of PARP-1 $1^{-1-}$ mice. UVB irradiation inhibited fluorochrome export from cultured spleen cells of wild-type mice (a). Treatment with PARP-1 inhibitors 3$A B$ and $D P Q(b, c)$ restored the export of fluorochrome from UVB-irradiated wildtype cells. Note that UVB irradiation did not influence the export of fluorochrome from PARP-1-null cells (d). UVB doses are depicted in $\mathrm{mJ} / \mathrm{cm}^{2}$. The decrease of the cellular fluorescence caused by export of CFS was measured by flow cytofluorometry. Significant $(P<0.05)$ and highly significant $(P<0.01)$ values were marked with single and double asterisks, respectively

\section{UVB-induced inhibition of ABC transporters is dependent on PARG activity}

Activated PARP-1 synthesises poly(ADP-ribose). Accumulation of poly(ADP-ribose) in the nucleus leads to nuclear translocation of poly(ADP-ribose)-glycohydrolase (PARG). ${ }^{25}$ PARG generates ADP-ribose by hydrolysis of poly(ADPribose). To investigate if PARG contributes to the inhibition of membrane transporters by UVB irradiation, we used gallotannin, a cell-permeable PARG inhibitor ${ }^{25}$ Gallotannin treatment prevented the inhibition of $A B C$ transporters following irradiation (Figure 5a). These data indicate that UVB-induced inhibition of $A B C$ transporters requires both PARP-1 and PARG activity.

\section{ADP ribose inhibits the activity of the $A B C$ transporter P-glycoprotein (Pgp)}

Nuclear PARG hydrolyses poly(ADP-ribose) and generates relatively high intracellular concentrations of ADP-ribose, which may compete with ATP for binding to ABC transporters. To test the hypothesis that ADP-ribose, which is not penetrating viable cells, mediates the UVB-induced inhibition of $A B C$ transporters, we employed inside-out membrane vesicles containing high amounts of the prototype $A B C$ transporter Pgp. ${ }^{26,27}$ ADP-ribose, at a concentration of $10 \mu \mathrm{M}$, caused a virtually complete inhibition of the activity of Pgp $(P=0.0015)$ (Figure 5b). Pgp activity was comparable to that observed in the absence of the pump 'fuel' ATP (Figure 5b). 


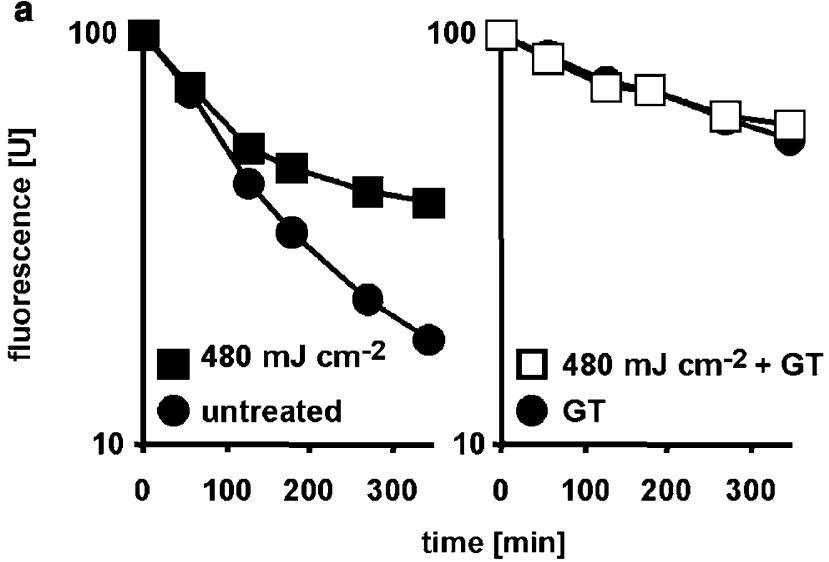

b

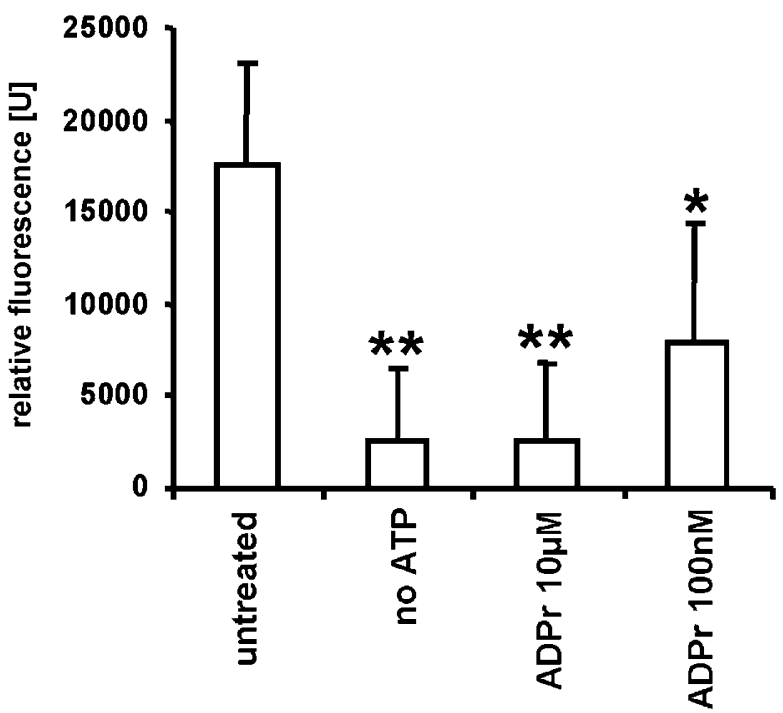

Figure 5 ADP-ribose, the product of concerted action of PARP-1 and PARG inhibits the transport function of Pgp. Cells pretreated with the PARG inhibitor gallotannin (GT) did not show any influence on the export of the fluorochrome CFS following irradiation (a). The transport activity of Pgp was assessed employing inside-out membrane vesicles from cells overexpressing Pgp (b). The accumulation of the fluorochrome in the membrane vesicles reflects the Pgp pumping activity. As negative controls, we used vesicles incubated with fluorochrome in the absence of ATP. Treatment with ADP-ribose significantly reduced Pgp function (b). Samples were analysed in pentaplicates. Significan $(P<0.05)$ and highly significant $(P<0.01)$ values were marked with single and double asterisks, respectively

Even at concentrations as low as $0.1 \mu \mathrm{M}$ ADP-ribose significantly inhibited the function of $\operatorname{Pgp}(P=0.03)$ (Figure $5 \mathrm{~b}$ ).

\section{Discussion}

DNA damage induces transient poly(ADP-ribosyl)ation of nuclear proteins in eukaryotic cells. ${ }^{28}$ This highly regulated process involves both PARP-1 and PARG 29. PARP-1 is activated by DNA strand breaks and synthesises and attaches a branched homopolymer of ADP-ribose to nuclear proteins. Poly(ADP-ribosyl)ation is involved in chromatin decondensation, DNA repair and replication, regulation of telomere function, and apoptosis. ${ }^{29,30}$ As soon as the level of
poly(ADP-ribose) exceeds a threshold (approximately $5 \mu \mathrm{M}$ ), cytoplasmic PARG is recruited to the nucleus. ${ }^{31}$ PARG hydrolyses the protein-bound poly(ADP-ribose), thereby generating free oligo- and monomers of ADP-ribose. ${ }^{30}$ This indicates that PARP-1 and PARG activities in response to DNA damage are closely coordinated. ${ }^{29}$

Using functional efflux assays, we provide evidence that UVB irradiation inhibits the activity of $A B C$ transporters. This effect was independent of apoptosis induction: it was observed in cells that did not display morphological features of apoptosis and was not influenced by treatment with the caspase inhibitor zVAD-fmk. Furthermore, induction of apoptosis by staurosporine did not inhibit the fluorochrome export.

UVB irradiation and consecutive activation of PARP-1 decreased the cellular ATP content. Therefore, the reduction of membrane transport may be the result of energy deprivation. However, staurosporine restored the membrane transport of irradiated cells although it further decreased the cellular ATP content. Indeed, staurosporine treatment of irradiated cells resulted in a membrane export even higher than of nonirradiated cells (not shown). Therefore, the quantification of the cellular ATP content showed a sufficient amount of ATP to fuel the membrane transporters in UVBirradiated cells. In conclusion, the loss of membrane export activity was not merely due to energy deprivation.

It has been shown that UVB irradiation induces intracellular $\mathrm{PN}$, due to reaction of NO with superoxide. ${ }^{22}$ Treatment of cells with PN mimicked the effect of UV irradiation. The strong oxidant PN is known to induce DNA damage ${ }^{13,32,33}$ and the repair is initiated by activation of PARP-1. ${ }^{23,34}$ We found that PARP-1 inhibitors restored fluorochrome export from irradiated cells, thus indicating that PARP-1 is required for the inhibition of membrane transport. The involvement of PARP-1 was further confirmed by the lack of response of PARP-1-null cells to irradiation.

Following PARP-1 activation, high amounts of ADP-ribose are generated by the action of PARG. ${ }^{29,30}$ Therefore, we checked the effect of the cell-permeable PARG inhibitor, gallotannin. ${ }^{25}$ UV irradiation had no influence on dye export from gallotannin-pretreated cells, suggesting that PARG plays an essential role in the inhibition of the membrane transport. Since gallotannin prevents the generation of ADP-ribose following DNA damage, ADP-ribose is a candidate inhibitor of $A B C$ transporters in irradiated cells. Using inside-out membrane vesicles containing $\mathrm{Pgp},{ }^{26,27}$ we demonstrated that ADP-ribose directly inhibits the export activity. Significant Pgp inhibition occurred at doses of ADP-ribose as low as $100 \mathrm{nM}$, quite below the level observed in cells exposed to oxidative stress $(5 \mu \mathrm{M}) .{ }^{31}$ ADP-ribose is a homologue of ADP and ATP that can also leave the nucleus and enter the cytosol. Therefore, it is tempting to speculate that ADP-ribose competes with ATP for its binding site on the cytosolic domains of Pgp and deprives the transporter of energy supply. Since the ATP-binding pockets of ABC transporters consist of highly conserved domains, ADP-ribose may also inhibit other members of the $A B C$ transporter superfamily.

In conclusion, our results indicate that UVB irradiation inhibits ATP-dependent membrane transporters. This effect is mediated by concerted action of PARP-1 and PARG. This 


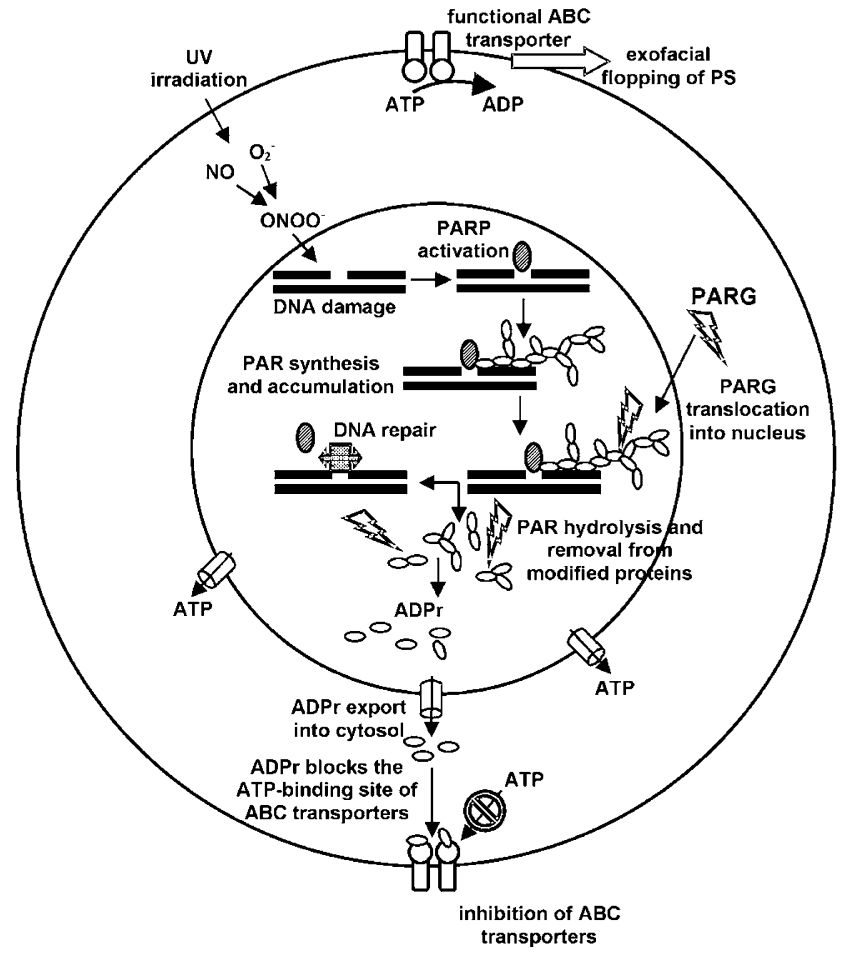

Figure 6 UV irradiation inhibits ATP-dependent membrane transporters via generation of ADP-ribose by the concerted action of PARP-1 and PARG. Abbreviations: nitric oxide $=\mathrm{NO}$, oxygen superoxide $=\mathrm{O}_{2}^{-}$, peroxynitrite $=\mathrm{ONOO}^{-}$, poly(ADP-ribose $)=\mathrm{PAR}, \mathrm{ADP}$-ribose $=\mathrm{ADPr}$, phosphatidylserine $=P S$

study provides new insights into a general mechanism regulating the activity of $A B C$ transporters (Figure 6). Since multiple drug resistance of tumour cells is known to rely on the functional activity of $A B C$ transporters, ${ }^{35,36}$ our results point towards new strategies which may contribute to the success of antineoplastic combined strategies.

\section{Materials and Methods}

\section{Cells and fluorochrome labelling}

Peripheral blood mononuclear cells (PBMC) and granulocytes were isolated from heparinised peripheral blood of normal healthy volunteers by standard density centrifugation. The isolated cells were washed twice with phosphate-buffered saline (PBS). In some experiments, plastic nonadherent cells were employed. To remove adherent cells, $2 \times 10^{6} \mathrm{ml}^{-1}$ PBMC were resuspended in Dulbecco's modified Eagle's medium (DMEM) and allowed to adhere to plastic at $37^{\circ} \mathrm{C}$ in a humidified atmosphere with $5 \% \quad \mathrm{CO}_{2}$ for $60-90 \mathrm{~min}$. The nonadherent cells (lymphocytes) were washed and resuspended in RPMI-1640 culture medium.

PARP- $1^{-1-}$ mice $^{37}$ were a generous gift from Dr. V Burkart (Diabetes Research Institute, Duesseldorf, Germany). Wild-type male mice 129/Sv and C57BI/6 (Charles River, Sulzfeld, Germany) were housed in a pathogen-free animal facility and treated in accordance with the European Community guidelines. Spleen and lymph node cells from PARP $-1^{-1-}$ mice and corresponding controls (129/Sv and C57Bl6 mice) were prepared as described ${ }^{38}$ and resuspended in culture medium.
Fluorochrome loading was performed by incubation of $1 \times 10^{7} \mathrm{celll} / \mathrm{ml}$ in PBS containing $2 \mu \mathrm{M}$ CFS diacetate ester (Molecular Probes, Leiden, The Netherlands) for $30 \mathrm{~min}$ at $37^{\circ} \mathrm{C} .{ }^{39}$ Further dye uptake was prevented by washes in ice-cold PBS. An aliquot of cells was put on ice for measurement of baseline fluorochrome uptake. In all cases, $1 \mu \mathrm{g} / \mathrm{ml}$ propidium iodide (PI) (Sigma, Munich, Germany) was added to the culture medium. PI-permeable necrotic cells were excluded from flow cytofluorometric analysis by gating on PI-negative cells. ${ }^{40}$ Labelling of cells with rhodamine 123 was performed by adding $5 \mu \mathrm{g} / \mathrm{ml}$ rhodamine 123 hydrate (Sigma) to the culture medium and incubating the cells at $37^{\circ} \mathrm{C}$ for $6 \mathrm{~h}$.

\section{Functional export assay}

To assess the functional dye export mediated by ATP-dependent membrane transporters, human and murine cells were cultured at 37 and $30^{\circ} \mathrm{C}$, respectively. The time course of the cellular fluorochrome export was monitored by two-colour flow cytofluorometry using an EPICS-XL ${ }^{\mathrm{TM}}$ flow cytofluorometer (Coulter, Hialeah, USA). In all experiments, forward scatter (FS) versus side scatter (SS) dot plots were used to strictly gate on viable cells. ${ }^{41}$ This gate contained less than $5 \%$ of annexin V-FITC-binding cells (Roche Biochemicals) ${ }^{40}$ and an even lower percentage of PIpermeable cells. Furthermore, PI-permeable cells were excluded from all analyses by electronic gating. To modulate the export of fluorochromes, we used 3-AB $(0.5 \mathrm{mM})$, cyclosporine A $\left(7.5 \mu \mathrm{gml}^{-1}\right)$, DPQ $(50 \mu \mathrm{M})$, gallotannin $(50-100 \mu \mathrm{M})$ (Fluka), oligomycin $(10 \mu \mathrm{M}), \mathrm{PN}(5$ and $10 \mu \mathrm{M})$, probenecid $(1 \mathrm{mM})$, staurosporine $(2 \mu \mathrm{M})$, sulphinpyrazone $(2.25 \mathrm{mM})$, verapamil $(30 \mu \mathrm{M})$, and zVAD-fmk $(5 \mu \mathrm{M})$. For UVB irradiation, cells were plated at $1 \times 10^{6} \mathrm{cells} / \mathrm{ml}$ in flat bottom 24-well tissue culture plates and irradiated with $3 \mathrm{~mJ} / \mathrm{cm}^{2}$.

\section{Quantification of cellular ATP}

For each condition, $10^{6}$ cells were harvested and disrupted by addition of $500 \mu \mathrm{l}$ of cold $10 \%$ trichloroacetic acid (Sigma) for $20 \mathrm{~min}$ on ice. After centrifugation at $30000 \mathrm{~g}$ for $10 \mathrm{~min}$, the supernatants were collected and extracted with two volumes of trioctylamine-freon (Sigma). ATP quantification was performed by luciferine/luciferase assay (Lumit 1243. 102 ATP Monitoring kit, Pharmacia LKB, Uppsala, Sweden, Lumac 2080 Lumac systems AG, Basel, Swiss).

\section{Assessment of Pgp activity using inside-out membrane vesicles}

The Pgp activity assay (Alexis Biochemicals, Grünberg, Germany) was performed according to the manufacturer's instructions. This system uses membrane vesicles that contain high amounts of $\mathrm{Pgp}^{26,27}$ The vesicles were immobilised on 96 -well microtiter plates by incubation at $37^{\circ} \mathrm{C}$ for $30 \mathrm{~min}$. The plates were washed with PBS to remove unattached vesicles. Then, the test samples were added in Ringer's solution and incubated for $20 \mathrm{~min}$ at $37^{\circ} \mathrm{C}$. The pumping reaction was started by consecutive addition of the fluorescent Pgp substrate, rhodamine, and the cofactor ATP, which supplies the energy for the transporter. After $20 \mathrm{~min}$ incubation at $37^{\circ} \mathrm{C}$ the samples were removed and the plates were washed to eliminate the unassimilated rhodamine. The fluorescence of the rhodamine that was pumped into the membrane sacs was measured after it was liberated from the vesicles by detergent lysis. This fluorescence represents a measure of the activity of the Pgp pump present in the membranes and was determined using a microfluorescence reader (emission of $485 \mathrm{~nm}$ and excitation of $530 \mathrm{~nm}$ wavelength). The extent of Pgp inhibition is measured 
by a decrease of the fluorescence signal. Samples with no addition of ATP served as negative control. This system was used to detect the direct influence of ADP-ribose (10 and $100 \mathrm{nM}$ ) on the activity of Pgp.

\section{Statistical analysis}

Statistical analyses were performed using the two-tailed Student's $t$-test for unpaired samples with unequal variance. $P$ values $(P)$ of less than 0.05 were considered statistically significant.

\section{Acknowledgements}

We thank Dr. V Burkart (Diabetes Research Institute, Duesseldorf, Germany) and Dr. ZQ Wang (International Agency for Research on Cancer, Lyon, France) for providing the PARP ${ }^{-1-}$ animals. This work was supported by grants of the Wilhelm Sander Foundation, by the Federal Ministry of Education and Research (BMBF) and the Interdisciplinary Center for Clinical Research (IZKF) at the University Hospital of the University of Erlangen-Nuremberg, and by the Staedtler Stiftung.

\section{References}

1. Klein I, Sarkadi B and Varadi A (1999) An inventory of the human ABC proteins. Biochim. Biophys. Acta 1461: 237-262

2. McAleer MA, Breen MA, White NL and Matthews N (1999) pAbc11 (also known as Moat-C and Mrp5), a member of the Abc family of proteins, has anion transporter activity but does not confer multidrug resistance when overexpressed in human embryonic kidney 293 cells. J. Biol. Chem. 274: 23541-23548

3. Dean M, Hamon Y and Chimini G (2001) The human ATP-binding cassette (ABC) transporter superfamily. J. Lipid Res. 42: 1007-1017

4. Decottignies A and Goffeau A (1997) Complete inventory of the yeast ABC proteins. Nat. Genet. 15: 137-145

5. Doige CA and Ames GF (1993) ATP-dependent transport systems in bacteria and humans: relevance to cystic fibrosis and multidrug resistance. Annu. Rev. Microbiol. 47: 291-319

6. Chambenoit O, Hamon Y, Marguet D, Rigneault H, Rosseneu M and Chimini G (2001) Specific docking of apolipoprotein A-I at the cell surface requires a functional ABCA1 transporter. J. Biol. Chem. 276: 9955-9960

7. Marguet D, Luciani MF, Moynault A, Williamson P and Chimini G (1999) Engulfment of apoptotic cells involves the redistribution of membrane phosphatidylserine on phagocyte and prey. Nat. Cell Biol. 1: 454-456

8. Hamon $Y$, Broccardo $C$, Chambenoit O, Luciani MF, Toti F, Chaslin S, Freyssinet JM, Devaux PF, McNeish J, Marguet D and Chimini G (2000) ABC1 promotes engulfment of apoptotic cells and transbilayer redistribution of phosphatidylserine. Nature 2: 399-406

9. Leith CP, Kopecky KJ, Chen IM, Eijdems L, Slovak ML, McConnell TS, Head DR, Weick J, Grever MR, Appelbaum FR and Willman CL (1999) Frequency and clinical significance of the expression of the multidrug resistance proteins MDR1/P-glycoprotein, MRP1, and LRP in acute myeloid leukemia: a Southwest Oncology Group Study. Blood 94: 1086-1099

10. Smeets ME, Raymakers RA, Vierwinden G, Pennings $A H$, Wessels $H$ and de Witte T (1999) Triggering noncycling hematopoietic progenitors and leukemic blasts to proliferate increases anthracycline retention and toxicity by downregulating multidrug resistance. Blood 94: 2414-2423

11. Liang BC and Ullyatt E (1998) Increased sensitivity to cisdiamminedichloroplatinum induced apoptosis with mitochondrial DNA depletion. Cell Death Differ. 5: 694-701

12. Leist M, Single B, Castoldi AF, Kuhnle S and Nicotera P (1997) Intracellular adenosine triphosphate (ATP) concentration: a switch in the decision between apoptosis and necrosis. J. Exp. Med. 185: 1481-1486

13. Lee YJ and Shacter E (1999) Oxidative stress inhibits apoptosis in human lymphoma cells. J. Biol. Chem. 274: 19792-19798
14. Andrei C, Dazzi C, Lotti L, Torrisi MR, Chimini G and Rubartelli A (1999) Unidirectional fluxes of rhodamine 123 in multidrug-resistant cells: evidence against direct drug extrusion from the plasma membrane. Mol. Biol. Cell. 10: 1463-1475

15. De Clerck LS, Bridts CH, Mertens AM, Moens MM and Stevens WJ (1994) Use of fluorescent dyes in the determination of adherence of human leucocytes to endothelial cells and the effect of fluorochromes on cellular function. J. Immunol. Methods 172: 115-124

16. Thomas WD, Zhang XD, Franco AV, Nguyen T and Hersey P (2000) TNFrelated apoptosis-inducing ligand-induced apoptosis of melanoma is associated with changes in mitochondrial membrane potential and perinuclear clustering of mitochondria. J. Immunol. 165: 5612-5620

17. Herr I, Wilhelm D, Meyer E, Jeremias I, Angel P and Debatin KM (1999) JNK/ SAPK activity contributes to TRAIL-induced apoptosis. Cell Death Differ. 6: 130-135

18. Benson RS, Dive C and Watson AJ (1998) Comparative effects of Bcl-2 overexpression and ZVAD.FMK treatment on dexamethasone and VP16-induced apoptosis in CEM cells. Cell Death Differ. 5: 432-439

19. Kashkar H, Kronke M and Jurgensmeier JM (2002) Defective Bax activation in Hodgkin B-cell lines confers resistance to staurosporine-induced apoptosis. Cell Death Differ. 9: 750-757

20. Tee AR and Proud CG (2001) Staurosporine inhibits phosphorylation of translational regulators linked to mTOR. Cell Death Differ. 8: 841-849

21. Hsu YT, Wolter KG and Youle RJ (1997) Cytosol-to-membrane redistribution of Bax and Bcl-X(L) during apoptosis. Proc. Natl. Acad. Sci. USA 94: 3668-3672

22. Deliconstantinos G, Villiotou V and Stavrides JC (1996) Increase of particulate nitric oxide synthase activity and peroxynitrite synthesis in UVB-irradiated keratinocyte membranes. Biochem. J. 320: 997-1003

23. Bank N, Kiroycheva M, Singhal PC, Anthony GM, Southan GJ and Szabo C (2000) Inhibition of nitric oxide synthase ameliorates cellular injury in sickle cell mouse kidneys. Kidney Int. 58: 82-89

24. Eliasson MJ, Sampei K, Mandir AS, Hurn PD, Traystman RJ, Bao J, Pieper A, Wang ZQ, Dawson TM, Snyder SH and Dawson VL (1997) Poly(ADP-ribose) polymerase gene disruption renders mice resistant to cerebral ischemia. Nat. Med. 3: 1089-1095

25. Ying W, Sevigny MB, Chen Y and Swanson RA (2001) Poly(ADP-ribose) glycohydrolase mediates oxidative and excitotoxic neuronal death. Proc. Natl. Acad. Sci. USA 98: 12227-12232

26. Hyafil $F$, Vergely C, Du Vignaud $P$ and Grand-Perret $T$ (1993) In vitro and in vivo reversal of multidrug resistance by GF120918, an acridonecarboxamide derivative. Cancer Res. 53: 4595-4602

27. Mistry P, Plumb J, Eccles S, Watson S, Dale I, Ryder H, Box G, Charlton $P$, Templeton D and Bevan PB (1999) In vivo efficacy of XR9051, a potent modulator of P-glycoprotein mediated multidrug resistance. Br. J. Cancer 79 : 1672-1678

28. Lautier D, Lagueux J, Thibodeau J, Menard L and Poirier GG (1993) Molecular and biochemical features of poly (ADP-ribose) metabolism. Mol. Cell Biochem. 122: 171-193

29. Davidovic L, Vodenicharov M, Affar EB and Poirier GG (2001) Importance of poly(ADP-ribose) glycohydrolase in the control of poly(ADP-ribose) metabolism. Exp. Cell Res. 268: 7-13

30. Lin W, Ame JC, Aboul-Ela N, Jacobson EL and Jacobson MK (1997) Isolation and characterization of the CDNA encoding bovine poly(ADP-ribose) glycohydrolase. J. Biol. Chem. 272: 11895-11901

31. Alvarez-Gonzalez R and Althaus FR (1989) Poly(ADP-ribose) catabolism in mammalian cells exposed to DNA-damaging agents. Mutat. Res. 218: 67-74

32. Rappold I, Iwabuchi K, Date T and Chen J (2001) Tumor suppressor p53 binding protein 1 (53BP1) is involved in DNA damage-signaling pathways. J. Cell Biol. 153: 613-620

33. Virag L, Szabo E, Bakondi E, Bai P, Gergely P, Hunyadi J and Szabo C (2002) Nitric oxide-peroxynitrite-poly(ADP-ribose) polymerase pathway in the skin. Exp. Dermatol. 11: 189-202

34. Virag $L$ and Szabo C (2002) The therapeutic potential of poly(ADP-ribose) polymerase inhibitors. Pharmacol. Rev. 54: 375-429

35. Chen CJ, Chin JE, Ueda K, Clark DP, Pastan I, Gottesman MM and Roninson IB (1986) Internal duplication and homology with bacterial transport proteins in the mdr1 (P-glycoprotein) gene from multidrug-resistant human cells. Cell 47: 381-389 
36. Cole SP, Bhardwaj G, Gerlach JH, Mackie JE, Grant CE, Almquist KC, Stewart AJ, Kurz EU, Duncan AM and Deeley RG (1992) Overexpression of a transporter gene in a multidrug-resistant human lung cancer cell line. Science 258: 1650-1654

37. Wang ZQ, Auer B, Stingl L, Berghammer H, Haidacher D, Schweiger M and Wagner EF (1995) Mice lacking ADPRT and poly(ADP-ribosyl)ation develop normally but are susceptible to skin disease. Genes Dev. 9: 509-520

38. Depraetere S, Verhoye L, Leclercq G and Leroux-Roels G (2001) Human B cell growth and differentiation in the spleen of immunodeficient mice. J. Immunol. 166: 2929-2936
39. Lyons AB (1999) Divided we stand: tracking cell proliferation with carboxyfluorescein diacetate succinimidyl ester. Immunol. Cell Biol. 77: 509515

40. Koopman G, Reutelingsperger CP, Kuijten GA, Keehnen RM, Pals ST and van Oers MH (1994) Annexin V for flow cytometric detection of phosphatidylserine expression on B cells undergoing apoptosis. Blood 84 $1415-1420$

41. Berndt C, Mopps B, Angermuller S, Gierschik P and Krammer PH (1998) CXCR4 and CD4 mediate a rapid CD95-independent cell death in CD4(+) T cells. Proc. Natl. Acad. Sci. USA 95: 12556-12561 